\title{
1 An effective workshop on "How to be an Effective Mentor for Underrepresented STEM
}

\section{Trainees"}

3 Andrea G. Marshall ${ }^{1}$, Caroline B. Palavicino-Maggio ${ }^{2}$, Elsie Spencer $^{3}$, Zer Vue $^{1}$, Heather

4 Beasley $^{1}$, Edgar Garza-Lopez ${ }^{4}$, Lillian Brady ${ }^{5}$, Zachary Conley ${ }^{6}$, Kit Neikirk ${ }^{7}$, Sandra Murray ${ }^{8}$,

5 Denise Martinez ${ }^{9}$, Haysetta Shuler ${ }^{10}$, Derrick Morton ${ }^{11 \#}$, Antentor Hinton, Jr. ${ }^{1,4 \#}$

\section{Author Information}

71 Department of Molecular Physiology and Biophysics, Vanderbilt University, Nashville, TN

82 Department of Neurobiology, Harvard Medical School, Boston, MA

93 Teachers College, Columbia University, New York, NY, 10027 USA

104 Hinton and Garza Lopez Family Consulting Company, Iowa City, IA

115 Department of Pharmacology, Vanderbilt University, Nashville, TN

126 Collaborative for STEM Education and Outreach, Department of Teaching and Learning,

13 Vanderbilt University, Nashville, TN

147 Department of Biology, University of Hawaii, Hilo, HI

158 Department of Cell Biology, University of Pittsburgh School of Medicine, Pittsburgh, PA

169 Department of Family Medicine, University of Iowa, Iowa City, IA

1710 Department of Biological Sciences, Winston-Salem State University, Winston-Salem, NC

1811 Department of Biological Sciences, University of Southern California, Los Angeles, CA 
bioRxiv preprint doi: https://doi.org/10.1101/2021.12.06.471498; this version posted December 19, 2021. The copyright holder for this preprint

(which was not certified by peer review) is the author/funder, who has granted bioRxiv a license to display the preprint in perpetuity. It is made available under aCC-BY-NC-ND 4.0 International license.

19 *These authors share co-first authorship

20 \#These authors share co-senior authorship

21 Co-Corresponding Author: antentor.o.hinton.jr@vanderbilt.edu

22 Co-Corresponding Author: mortond@usc.edu

23

24 


\section{Abstract}

26 Despite an increase in programming to promote persons excluded by their ethnicity or race

27 (PEER) scholars, minorities remain underrepresented in many STEM programs. The academic

28 pipeline is largely leaky for underrepresented minority (URM) scholars due to a lack of effective

29 mentorship. Many URM students experience microaggressions and discrimination from their

30 mentors due to a lack of quality mentorship training. In this workshop, we provide a framework

31 for how to be an effective mentor to URM trainees. Mentees, especially URM trainees, can

32 flourish in effective mentoring environments where they feel welcomed and can comfortably

33 develop new ideas without feeling threatened by external factors. Effective mentoring

34 environments provide motivational support, empathy, cultural competency, and training.

35 Keywords Diversity, STEM, Professional Development, Higher Education, Mentorship,

36 Culturally Supportive, Cultural Competence 


\section{The framework of the workshop}

Designing an effective mentorship workshop requires examples of the characteristics of effective mentors of underrepresented minority (URM) trainees, a blueprint for selecting mentees

41 based on the mentorship environment, and strategies for maintaining nurturing mentor-mentee

42 relationships. Mentor-mentee relationships require navigating unique challenges to ensure the

43 success of URM trainees. Frequently, URM students face microaggressions, imposter fear, and

44 difficulties in building networks and mentorship relationships, which increase the risk of falling

45 out of the academic pipeline (Hinton Jr et al. 2020a; National Academies of Sciences 2020;

46 Shuler et al. 2021; Uddin and De Los Reyes 2021). Despite the nature of these challenges, based

47 on scientific findings, URM trainees perform better under supportive mentorship relationships,

48 which can help them overcome the daily challenges that deters them from staying in the

49 academic pipeline (Hinton Jr et al. 2020a; Termini et al. 2021a).

During the workshop strategies were presented to help potential mentors identify best

51 practices for effective and motivational mentoring. The importance of celebrating the mentee and

52 their journey was emphasized in the workshop, in addition the mentor was provided strategies

53 for identifying mentees in need of special guidance. These strategies encouraged mentors to

54 reframe how they think about students, work to have a more authentic mentor-mentee

55 relationships, and develop a motivation-based mentoring approach based on emotional

56 intelligence (Gardenswartz, Cherbosque and Rowe 2010; Opengart and Bierema 2015;

57 Montgomery 2017; Hinton et al. 2020; Hinton Jr et al. 2020b; Shuler et al. 2021).

58 In the workshop, all participants were presented with a model of intentional mentorship. This

59 mentoring model emphasizes a willingness to learn and establish credibility while facilitating the 
60 formation of positive relationships through networking (Shuler et al. 2021). Workshop

61 participants were also exposed to effective and ineffective mentorship practices (Neikirk 2021).

62 Furthermore, the workshop discussed using motivational mentoring as a way to cultivate the

63 mentee's spirit of excellence as they navigate their career development -- through the use of

64 individual development plans (IDP) (National Academies of Sciences 2020; Shuler et al. 2021).

65 These strategies are especially useful for mentees during times of hardship, such as classroom

66 challenges. (McReynolds et al. 2020; Termini et al. 2021b).

Introduction

69 Mentoring relationships are essential for the development of a mentee's career, especially those

70 from URM groups. Successful mentoring requires environments that bolster motivational

71 ambition, provides empathy, and utilizes cultural competency. Toxic mentoring environments

72 arise from poor communication, lack of commitment and experience, conflicting personalities,

73 perceived competition, poor perceived performance, and difficulty in forming interpersonal

74 connections with the mentee.

75 Key goals for successfully mentoring diverse trainees:

76 - Practice meditation and mindfulness

77 - Be aware of your own biases

78 - Create a positive environment

79 - Respond, do not react 
- Promote self-motivation, encompass your inner resources to act, reach, and achieve goals and aspirations

- Provide constructive, not deconstructive, criticisms

- Cultural competence

84 Motivational Support: How to motivate and support diverse trainees simultaneously?

85 Motivation is the inner drive to excel, which is often changed by internal and/or external conflict.

86 This inner drive is important for cultivating goals and providing direction. A trainee's motivation

87 governs the direction of the trainee's behavior in any mentoring environment, such as their

88 effort, grit, and attitude. Minority trainees not only face external barriers during their educational

89 and career journey, such as toxic mentorship and institutional inequities, but also experience

90 internal challenges, such as John Henryism (Rolle et al. 2021). Furthermore, URM also face

91 barriers including imposter fear, also known as imposter syndrome which is discussed in the

92 workshop as a stigmatizing word that places the issue on the individual as opposed to the

93 environment (Hinton Jr et al. 2020b; Rolle et al. 2021). These barriers stimulate a lack of

94 confidence, which affects their perseverance. Since all trainees have different motivations,

95 mentors should personalize their mentorship approach based on their mentee's goals and

96 motivations. A single mentorship strategy is often insufficient for a diverse group of mentees.

97 Mentees differ physically and emotionally, including in their motor, moral, and learning abilities.

98 Mentors set an example for their trainees. Quality mentoring comes from being an inspiration

99 (Shuler et al. 2021). Mentorship is an investment, not only to their institutions but to society as

100 their mentees may make substantial contributions (Hinton Jr et al. 2020b; Shuler et al. 2021).

101 Thus, the mentor's character can play a big role in how mentees view themselves. An inspiring 
102 mentor listens, serves, shares, focuses on positivity, stays authentic, is willing to learn, and

103 remains humble. Minority trainees excel with positive reinforcement. Mentors foster positivity in

104 their relationships with mentees. Mentors must also identify and restrain negative beliefs that

105 may influence their guidance and be willing to accept constructive feedback.

\section{Providing support and empathy}

107 Mentors need to invest time in getting to know their mentees. Active listening is as important as

108 intentional mentoring. An effective mentor sets aside time to speak with their mentees and pays

109 attention to what they have to say (Shuler et al. 2021). Active listening, instead of passive

110 listening, entails action. For example, if your mentee makes you aware of a concern or question,

111 the mentor might not have an answer to a specific situation, which would require seeking out

112 advice from their network. Intentional listening is essential to effectively communicate with

113 mentees. For example, if a mentor does not completely understand their trainees' questions or

114 concerns, the mentor may consider asking for clarification, which ensures a clear line of

115 communication between the mentor and mentee (Shuler et al. 2021). Active listening also

116 requires avoiding distractions, such as emails, while providing their mentees with undivided

117 attention. Focus on clarifying the situation to best provide an answer or suggestion. It is also

118 important a mentor maintains an open mind. Obstacles and setbacks are a good way for mentees

119 and mentors to grow and develop their skills.

120 Furthermore, each challenge is unique. Although mentees may be of the same gender,

121 racial/ethnic background, socio-economic background, or school systems, they are all individuals

122 with different journeys and motivations. No racial/ethnic group is monochromic hence it is

123 essential to develop a personalized 'individual development plan’ (IDP) (Hinton Jr et al. 2020b). 
124 Effective mentors also seek to maintain transparency by breaking down communication barriers,

125 including seeking out alternative approaches, media, or technology to carry out conversations.

126 It is also important for mentors to focus on developing their emotional intelligence (EI), which is

127 also known as emotional quotient or emotional intelligence quotient (Hinton Jr et al. 2020b,

128 Shuler et al. 2021). EI is the ability of understanding feelings, emotional language, and signals

129 conveyed by emotions (Hinton Jr et al. 2020b, Shuler et al. 2021).. EI involves distinguishing

130 and managing our personal feelings and interactions from those of other people (Hinton Jr et al.

131 2020b, Shuler et al. 2021). EI assists with managing your behavior, navigating social areas, and

132 helping others make critical life choices (Hinton Jr et al. 2020b, Shuler et al. 2021). EI also helps

133 identify personal biases in thinking (Hinton Jr et al. 2020b, Shuler et al. 2021). It is like a

134 window to determine why a mentee or colleague behaves a certain way or avoids making certain

135 decisions. Practicing empathy towards their mentees can help mentors and mentees communicate

136 more efficiently.

\section{Cultural competency and training}

138 Cultural competence is the knowledge and skills needed to work with a diverse group in a

139 meaningful relevant and productive way. Cultural competence involves an understanding of the

140 role of religion, community, and culture in the lives and careers of underrepresented minority

141 mentees. Mentors should familiarize themselves with common racial insensitivities and develop

142 methods to ask questions on these topics with sensitivity \& avoid perpetuating racial macro- and

143 microaggressions.

144 Based on these concepts, we tested how students perceived the information and whether they 145 could apply it to their career development and individual development plan. In this particular 
bioRxiv preprint doi: https://doi.org/10.1101/2021.12.06.471498; this version posted December 19, 2021. The copyright holder for this preprint (which was not certified by peer review) is the author/funder, who has granted bioRxiv a license to display the preprint in perpetuity. It is made available under aCC-BY-NC-ND 4.0 International license.

146 questionnaire, we used four questions to gauge interest. The questions consisted of a 10-point

147 scale that was based on rating the following concepts: overall presentation, support team, verbal

148 and nonverbal communication skills, and networking. 


\section{Methods}

151 Twenty-four students from Winston-Salem State University (a historically Black public

152 university) attended a 90-minute virtual workshop. The participants completed an anonymous

153 questionnaire before and after the workshop to gauge their expectations and satisfaction

154 regarding the workshop (Table 1). The data were compared using nonparametric Wilcoxon

155 matched-pairs and signed-rank tests to determine differences between measures. Differences

156 were considered statistically significant when $\mathrm{P}$ values were less than $0.05 . * * * * \mathrm{P}<0.0001$;

$157 * * * \mathrm{P}<0.001 ; * * \mathrm{P}<0.01 ; * \mathrm{P}<0.05 ; \mathrm{NS}$, not significant $\mathrm{P}>0.05 ;$ NS (not significant).

\section{Results}

We summarized the data from the questionnaires using box and whisker plots in which

160 the red centerline denotes the median, and error bars denote the standard error. Individual values

161 are represented by circles. Overall, participant feedback was positive. Responses to the pre-

162 workshop questionaries suggest that mentees did not initially believe the workshop would be

163 beneficial (Figure 1A-D, Pre-Test). The data suggests that their low expectations may be a result

164 of low exposure or lack of mentorship.

166 Thomas, Willis and Davis 2007; Janis and Barker 2016). However, after the workshop, feedback

167 scores increased by an average of 5.2 points on a 10-point scale. The median score was a 9 or

168 higher for every question asked (Figure 1A-D, Post-Test), indicating that the workshop was

169 found favorable and helpful for identifying mentors or considering mentors for other parts of

170 their lives. 
All post-workshop questionaries show a significant difference compared with pre-

172 workshop questions. Initially, on average, participants believed the workshop to be low to

173 moderately informative with an average evaluation of 4.1 (Figure 1A, Pre-Test). Following the

174 workshop, the average score increased by 4.8 to an overall average of 8.9 , indicating most

175 participants enjoyed the workshop (Figure 1A, Post-Test). Similarly, the average initial score for

176 believing the workshop would help improve communication skills was 5.2 (Figure 1B, Pre-Test).

177 Post-workshop, the average score increased by 4.8 points to an average of 9.9 (Figure 1B, Post-

178 Test). The belief that the workshop would increase networking skills increased by 5.6 points; the

179 average pre-test score was 3.9, while the average post-test score was 9.5 (Figure 1C). More so,

180 initially, participants did not strongly believe the workshop would underscore the importance of

181 having a support team, giving an average score of 3.6 (Figure 1D, Pre-Test). Following the

182 workshop, this score rose by 5.7 to an average of 9.3 (Figure 1D, Post-Test). The metrics

183 measured showed that, on average, mentees found the workshop informative and beneficial to

184 developing their networking, communication, and collaboration skills (Figure 1A-D, Post-Test).

185 These workshops allow for trainees to explore concepts about adequate mentorship

186 (Figure 1A-D). It is possible to interpret the data that initially students did not see the benefit of

187 the workshop because they may have felt it was not specifically targeting them or irrelevant to

188 their goals of developing a career at the undergraduate level (Figure 1A-D, Pre-Test). It is

189 important to highlight that the students did achieve a sense of award from gleaning new

190 information about mentorship. Taken together, these results suggest that career development

191 workshops focused on mentorship may have a large impact on student development and

192 performance level at the undergraduate level (Figure 1A-D).

\section{Discussion}


194 Mentoring is an important aspect of a mentee's career, especially those from URM groups

195 (Hinton Jr et al. 2020a, 2020b). Taken together, the data from the questionnaire highlights the

196 need for more career development opportunities focused on mentorship. This workshop also

197 provided an opportunity for self-reflection for students to understand the importance of mentors

198 and how they may be an important asset to achieving career goals. This workshop also provided

199 a unique understanding of different mentoring practices, and which may be most effective or

200 ineffective in a mentee-mentor relationship. Initially, enthusiasm for this type of program was

201 low and students thought career development workshops were not essential to their development

202 (Figure 1A-D, Pre-Test). However, the post-test results suggest that the students found this

203 workshop offered a robust set of strategies and tools to use in their career development and an

204 understanding of what type of mentor-mentee relationships they may need (Figure 1A-D, Post-

205 Test).

Although our sample size was small, the data suggest that career development workshops

207 are important for career advancement. We would further speculate that career advancement can

208 be done within mentee-mentor relationships, as well as, through skill and knowledge-building

209 workshops. We also suggest that students that experience this workshop can improve their

210 overall skill set and help build an understanding of the need for introspection and evaluation of

211 what may be helpful in their career advancement.

213 ethnicity, age, or sex. We suggest these workshops be given in other languages based on

214 institutional demographics to effectively communicate the importance of career development to

215 non-native speakers. Additionally, our study participants, although involved in STEM fields,

216 may not represent the entire student-body population. Thus, we suggest that this workshop and 
217 others be used to create a series to further enrich undergraduate career development across a

218 wide variety of demographics. Equally, we suggest that workshops like these continue to be a

219 resource to individuals that do not have access to career development opportunities. These

220 workshops should be open access for others to disseminate the information and help broaden the

221 true participation and motivation needed to pursue a STEM career. Furthermore, additional study

222 is needed to identify additional areas that may aid in student success.

\section{Availability of data and materials:}

224 A PowerPoint presentation of the workshop is available in English and Spanish upon request.

225 Survey data may be made available upon reasonable request.

\section{Acknowledgements:}

227 We thank the 24 students who participated in our survey.

228 Funding:

229 This work was supported by the UNCF/BMS EE Just Grant, Burroughs Wellcome Fund CASI

230 Award, Burroughs Welcome Fund Ad-hoc Award, NIH SRP Subaward to \#5R25HL106365-12

231 from the NIH PRIDE Program, DK020593, Vanderbilt Diabetes and Research Training Center

232 for DRTC Alzheimer's Disease Pilot \& Feasibility Program, UNCF/BMS EE Just Faculty Fund

233 Grant awarded to A.H.J.; 1K99GM141449-01 MOSAIC grant to C.P.M. and NSF grant MCB

$234 \quad \# 2011577$ I and NIH T32 5T32GM133353 to S.A.M.

235 Ethics Declaration, Project Title: Promoting Engagement in science for underrepresented

236 Ethnic and Racial minorities (P.E.E.R), 21-MortonD-HSR-SOM-01, Kaiser Foundation

237 Research Institute FWA: FWA00002344 
Ethics Approval and consent to participate: Yes

239 Consent for publication: Yes

240 Competing interests: Authors declare that they have no competing interests.

\section{References:}

Gardenswartz L, Cherbosque J, Rowe A. Emotional intelligence and diversity: A model for differences in the workplace. Journal of Psychological Issues in Organizational Culture 2010;1:74-84.

Hinton AO, McReynolds MR, Martinez D et al. The power of saying no. EMBO Rep 2020;21, DOI: 10.15252/embr.202050918.

Hinton Jr AO, Termini CM, Spencer EC et al. Patching the leaks: Revitalizing and reimagining the STEM pipeline. Cell 2020a;183:568-75.

Hinton Jr AO, Vue Z, Termini CM et al. Mentoring minority trainees: minorities in academia face specific challenges that mentors should address to instill confidence. EMBO reports 2020b;21:e51269.

Janis JE, Barker JC. Medical student mentorship in plastic surgery: the mentor's perspective. Plastic and reconstructive surgery 2016;138:925e-35e.

McReynolds MR, Termini CM, Hinton AO et al. The art of virtual mentoring in the twenty-first century for STEM majors and beyond. Nature Biotechnology 2020;38:1477-82.

257 Montgomery BL. Mapping a mentoring roadmap and developing a supportive network for strategic career advancement. Sage Open 2017;7:2158244017710288.

National Academies of Sciences E and Medicine. The science of effective mentorship in STEMM. 2020.

261 Neikirk K. Unique struggles and the ways mentorship can fail. Cell Mentor 2021.

262 Opengart R, Bierema L. Emotionally intelligent mentoring: Reconceptualizing effective 263 mentoring relationships. Human Resource Development Review 2015;14:234-58.

264 Packard BW-L. Web-based mentoring: Challenging traditional models to increase women's 265 access. Mentoring and Tutoring 2003;11:53-65. 
Rolle T, Vue Z, Murray S et al. Toxic stress and burnout: John henryism and social dominance in the laboratory and STEM workforce. Pathogens and Disease 2021, DOI: 10.1093/femspd/ftab041.

Shuler H, Cazares V, Marshall A et al. Intentional mentoring: maximizing the impact of underrepresented future scientists in the 21st century. Pathogens and Disease 2021;79:ftab038.

Termini CM, Hinton Jr AO, Garza-López E et al. Building Diverse Mentoring Networks that Transcend Boundaries in Cancer Research. Trends in Cancer 2021a.

274 Termini CM, McReynolds MR, Rutaganira FU et al. Mentoring during Uncertain Times. Trends in Biochemical Sciences $2021 \mathrm{~b}$.

Thomas KM, Willis LA, Davis J. Mentoring minority graduate students: Issues and strategies for institutions, faculty, and students. Equal Opportunities International 2007.

Uddin LQ, De Los Reyes A. Cultivating allyship through casual mentoring to promote diversity. Trends in Cognitive Sciences 2021. 
292 Table 1. Pre- and post-workshop evaluations.

\begin{tabular}{|l|l|}
\hline \multicolumn{1}{|c|}{ Pre-workshop survey questions } & \multicolumn{1}{|c|}{ Post-workshop survey questions } \\
\hline On a scale of 1 to 10, do you think the & On a scale of 1 to 10, how did you like the \\
presentation will keep you well informed? & presentation? \\
\hline $\begin{array}{l}\text { On a scale of } 1 \text { to } 10, \text { how do you think the } \\
\text { talk will improve your verbal and non-verbal }\end{array}$ & On a scale of 1 to 10, how do you think the talk \\
communication? & communication? \\
\hline On a scale of 1 to 10, how well do you think & On a scale of 1 to 10, how much do you think the \\
the talk will improve your networking skills? & talk helped you improve your networking skills? \\
\hline On a scale of 1 to 10, how do you think the & On a scale of 1 to 10, how much do you think the \\
talk will improve your understanding of what a & talk helped you improve your understanding of \\
\hline
\end{tabular}


300 Figure Legend 1. Results from pre- and post-workshop evaluations. These pre- and post-

301 workshop questions were also used to evaluate mentees' knowledge regarding mentee-mentor

302 relationships. A. The informativeness of the workshop. B. How much the workshop improved

303 communication skills. C. How much the workshop improved networking skills. D. How much

304 the workshop improved understanding of support teams and assistive roles. 

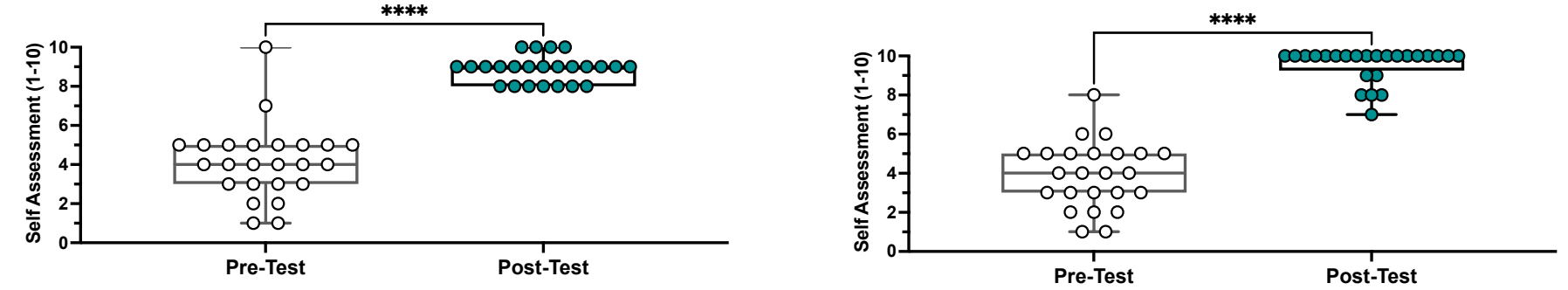

B

Helped me improve my communication skills

D Helped me improve my understanding of the role of a support team
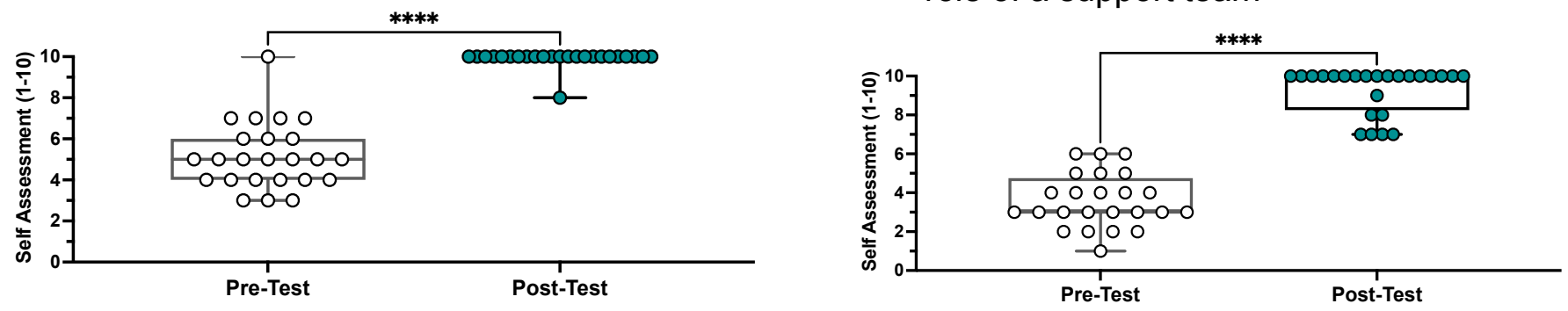